\title{
A rich vehicle routing problem arising in the replenishment of automated teller machines
}

\author{
Çă̆rı $\operatorname{Koç}^{a}$, Mehmet $\operatorname{Erbaş}^{b}$, Eren Özceylan ${ }^{c^{*}}$ \\ ${ }^{a}$ Department of Business Administration, Social Sciences University of Ankara, Ankara, Turkey \\ ${ }^{b}$ General Directorate of Mapping, Ministry of National Defense, Ankara, Turkey \\ ${ }^{c}$ Department of Industrial Engineering, Gaziantep University, Gaziantep, Turkey \\ cagri.koc@asbu.edu.tr,mehmet.erbas@hgk.msb.gov.tr,erenozceylan@gmail.com
}

\begin{tabular}{|c|c|}
\hline ARTICLE INFO & ABSTRACT \\
\hline $\begin{array}{l}\text { Article History: } \\
\text { Received } 29 \text { December } 2017 \\
\text { Accepted } 26 \text { July } 2018 \\
\text { Available } 31 \text { July } 2018\end{array}$ & \multirow{3}{*}{$\begin{array}{l}\text { This paper introduces, models, and solves a rich vehicle routing problem (VRP) } \\
\text { motivated by the case study of replenishment of automated teller machines } \\
\text { (ATMs) in Turkey. In this practical problem, commodities can be taken from } \\
\text { the depot, as well as from the branches to efficiently manage the inventory } \\
\text { shortages at ATMs. This rich VRP variant concerns with the joint multiple de- } \\
\text { pots, pickup and delivery, multi-trip, and homogeneous fixed vehicle fleet. We } \\
\text { first mathematically formulate the problem as a mixed-integer linear program- } \\
\text { ming model. We then apply a Geographic Information System (GIS)-based } \\
\text { solution method, which uses a tabu search heuristic optimization method, to a } \\
\text { real dataset of one of the major bank. Our numerical results show that we are } \\
\text { able to obtain solutions within reasonable solution time for this new and chal- } \\
\text { lenging practical problem. The paper presents computational and managerial } \\
\text { results by analyzing the trade-offs between various constraints. }\end{array}$} \\
\hline $\begin{array}{l}\text { Keywords: } \\
\text { Vehicle routing } \\
\text { GIS } \\
\text { Tabu search } \\
\text { Replenishment of automated teller } \\
\text { machines }\end{array}$ & \\
\hline $0-00,90 D 0$ & \\
\hline
\end{tabular}

\section{Introduction}

In logistics operations, fulfilling consumer demands for diverse and premium products is an important challenge [1]. The classical vehicle routing problem (VRP) aims to determine an optimal routing plan for a fleet of homogeneous vehicles to serve a set of customers, such that each vehicle route starts and ends at the depot, each customer is visited once by one vehicle, and some side constraints are satisfied. Many variants and extensions of the VRP have intensively studied in the literature. For further details about the VRP and its variants, we refer the reader to Laporte [2] and Toth and Vigo [3].

Over the last years, several variants of multiconstrained VRPs have been studied, forming a class of problems known as Rich VRPs. Lahyani et al. 4 presented a comprehensive and relevant taxonomy for the literature devoted to Rich VRPs. The authors have investigated 41 articles devoted to rich VRPs in detail, and developed an elaborate definition of RVRPs.

Karaoglan et al. [5] studied aircraft routing and scheduling for cargo transportation in an airline company in Turkey. Karagul and Gungor [6] studied the mixed fleet VRP to optimize the distribution of the tourists who have traveled between the airport and the hotels in Turkey. The authors developed a Savings algorithm, a Sweep algorithm and a random permutation alignment. Furthermore, a genetic algorihm and random search algorithms algorithms are also developed. Van Anholt et al. [7] introduced, modeled, and solved a rich multiperiod inventory-routing problem with pickups and deliveries motivated by the replenishment of automated teller machines (ATMs) in

*Corresponding Author 
the Netherlands. The authors first decomposed the problem into several more manageable subproblems by means of a clustering procedure, and they simplified the subproblems by fixing some variables. Valid inequalities are then generated to strength the resulting subproblems. An efficient branch-and-cut algorithm is then developed. Karagul et al. [8] used 2-Opt based evolution strategy for travelling salesman problem.

A variant of the VRP known as multiple depots VRP, in which more than one depot is considered, studied by many researchers. Crevier et al. [9] considered the multiple depots VRP with interdepot routes. Braekers et al. 10 proposed exact and meta-heuristic approach for a general heterogeneous dial-a-ride problem with multiple depots. Contardo and Martinelli [11] developed a new exact algorithm for the multiple depots VRP under capacity and route length constraints. For further details about the multiple depots VRP and its variants, we refer the reader to the review paper of Montoya et al. [12]. Another interesting variant is multi-trip VRP, in which vehicles can perform several trips per day, because of their limited number and capacity [13-15].

An important family of routing problems is pickup-and-delivery problems (PDPs) in which goods have to be transported from different origins to different destinations. In one-to-one variant of PDPs, each customer demand consists of transporting a load from one pickup node to one destination node. Many exact and heuristic methods are developed for this problem variant which is usually referred to as the pickup-and-delivery VRP. Xu et al. [16] studied a rich PDP with many side constraints. Sigurd et al. [17] considered the transportation of live animals. For further details about the PDPs and its variants, we refer the reader to Battarra et al. [18, Berbeglia et al. [19, Koç and Laporte [20], and Parragh et al. [21,22].

In recent years, Geographical Information System (GIS)-based solution methods used to solve several optimization problems. Casas et al. [23] developed an automated network generation procedure for routing of unmanned aerial vehicles in a GIS environment. Bozkaya et al. 24] studied the competitive multi-facility location-routing problem and presented a hybrid heuristic algorithm. The method is applied on a case study arising at a supermarket store chain in the city of Istanbul. The authors used genetic algorithm for the location part, and tabu search of GIS-based solution method for the VRP part. Samanlioglu [25] developed a multi-objective location-routing problem and described a mathematical model. The author used a GIS software to obtain the data related to the Marmara region of Turkey. Yanik et al. [26] considered the capacitated VRP with multiple pickup, single delivery and time windows, and proposed a hybrid metaheuristic approach. The method integrates a genetic algorithm for vendor selection and allocation, and a GIS-based solution method which uses a modified savings algorithm for the routing part. Krichen et al. [27] studied the VRP with loading and distance constraints and used a GIS solution method to solve the problem.

Our study is motivated by the problem faced by one of the major bank of Turkey operating in the city of Gaziantep. We consider a multi-depot, multi-trip, pick-up and delivery with homogenous vehicle fleet. We first define this new problem and presented a mathematical formulation. We then used a GIS-based solution approach employs a tabu search algorithm which can be used to store, analyze and visualize all data as well as model solutions in geographic format. We considered a real dataset of the bank and applied our GIS-based solution approach. We finally provide several managerial and policy insights by exploring the trade-offs between various constraints.

The remainder of this paper is structured as follows. Section 2 presents the problem definition and mathematical formulation. Section 3 describes the solution approach. Section 4 presents a case study with input data. Section 5 presents the solutions we propose. Finally, Section 6 provides our conclusions.

\section{Problem definition and mathematical formulation}

The problem is defined on a complete directed graph $\mathcal{G}=(\mathcal{N}, \mathcal{A})$. The location of each ATM, branch, and the district office is represented by a node. $\mathcal{N}=\{0\} \cup \mathcal{N}_{b} \cup \mathcal{N}_{c}$ is a set of nodes in which " $\{0\}$ " is the district office node, $\mathcal{N}_{b}$ is a set of branch nodes, and $\mathcal{N}_{c}$ is a set of ATM nodes. $\mathcal{A}=\{(i, j): i \in \mathcal{N}, j \in \mathcal{N}, i \neq j\}$ is the set of arcs. Each arc $(i, j) \in \mathcal{A}$ has a nonnegative distance $d_{i j}$. Each arc $(i, j) \in \mathcal{A}$ has a nonnegative travel time $c_{i j}$. Each ATM $i \in \mathcal{N}_{c}$ has a demand $q_{i}$ and a service time $p_{i}$. A fixed number of limited homogeneous vehicle fleet $m$ is available. The index set of routes is denoted by $\mathcal{R}=\{1, \ldots, r, \ldots\}$. The capacity of a vehicle is denoted by $Q$. The maximum allowed working duration is $T_{\max }$ for each vehicle. We use the real network distances when we computing the $d_{i j}$ values on each arc $(i, j) \in A$. Therefore, it is possible that $d_{i j} \neq d_{j i}$, 
i.e., asymmetric, which are illustrated in Figure 1 .

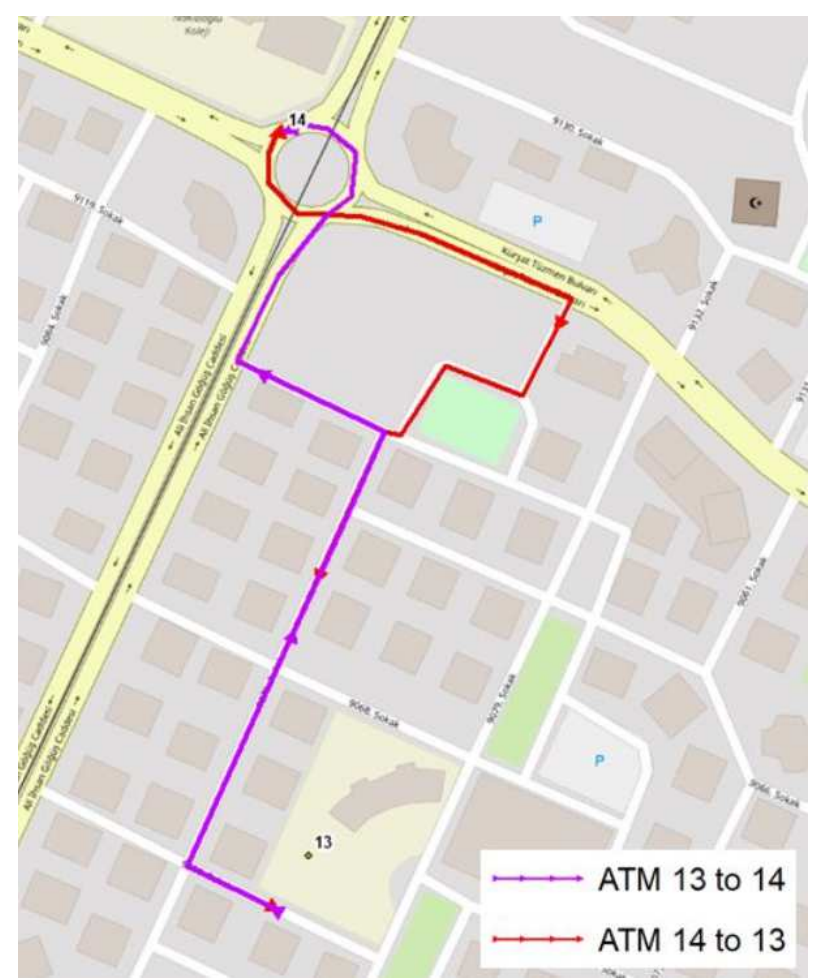

Figure 1. An example of asymmetric case from ATM 13 to 14, and from ATM 14 to 13 .

To formulate the problem, we define the following decision variables. Let $x_{i j r}$ be equal to 1 if a vehicle travels directly from node $i$ to node $j$ on route $r \in \mathcal{R}$. Let $f_{i j r}$ be the amount of commodity flowing on $\operatorname{arc}(i, j) \in \mathcal{A}$ by a vehicle on route $r \in \mathcal{R}$.

In our problem, one considers a homogeneous fixed fleet of vehicles, as well as a set of ATMs with known demands. The demand of each ATM is expressed as money tray and each vehicle are designed to satisfy these specific ATM demands. The bank has variable number of orders from ATMs which can be fulfilled by both district office and several branches. The journey of a vehicle which carries demanded money starts from district office and it begins to visit ATMs to load ordered money. If the money of a vehicle is finished before meeting the demand of ATMs, vehicle has two options. While the first option is to go back to district office, the second option is to go a branch to get money. Vehicles can perform several tours per day because of their limited number and capacity. The objective is to minimise the total en-route time of vehicles. Due to the minimization of total en-route time time in this problem, the vehicle visits district office or branch which is closer to it. This rich VRP variant is concerned with the joint multiple depots, pickup and delivery problems, multi-trip, and homogeneous fixed vehicle fleet.

The mathematical formulation of the problem is given as follows:

$$
\text { Minimize } \sum_{(i, j) \in \mathcal{A}} \sum_{r \in \mathcal{R}} c_{i j} x_{i j r}
$$

subject to

$$
\begin{aligned}
& \sum_{j \in \mathcal{N}} x_{0 j 1} \leq m \\
& \sum_{j \in \mathcal{N}} \sum_{r \in \mathcal{R}} x_{i j r}=1
\end{aligned}
$$

$\sum_{i \in \mathcal{N}} \sum_{r \in \mathcal{R}} x_{i j r}=1$

$\sum_{j \in \mathcal{N}_{c}} x_{0 j r} \geq \sum_{j \in \mathcal{N}_{c}} x_{0 j, r+1}$ $r \in \mathcal{R}: r<|\mathcal{R}|$

$\sum_{j \in \mathcal{N}} \sum_{r \in \mathcal{R}} f_{j i r}-\sum_{j \in \mathcal{N}} \sum_{r \in \mathcal{R}} f_{i j r}=q_{i}$

$q_{j} x_{i j r} \leq f_{i j r} \leq\left(Q-q_{i}\right) x_{i j r}$ $(i, j) \in \mathcal{A}, r \in \mathcal{R}$

$\sum_{(i, j) \in \mathcal{A}} \sum_{r \in \mathcal{R}} c_{i j} x_{i j r} \leq T_{\max }$

$x_{i j r} \in\{0,1\}$ $(i, j) \in \mathcal{A}, r \in \mathcal{R}$

$f_{i j r} \geq 0$

$(i, j) \in \mathcal{A}, r \in \mathcal{R}$.

The objective function (11) minimizes the total enroute time. Constraints (2) bounds the number of vehicles. Constraints (3) and (4) ensure that each customer is visited exactly once. Constraints (5) impose that a vehicle cannot start route $r+1$ before finish route $r$. Constraints (6) and (7) define the flows. Constraints (81) ensure that the total travel time cannot exceed the maximum allowed working duration. Finally, constraints (9) and (10) enforce the integrality and nonnegativity restrictions on the variables.

\section{Solution approach}

The mathematical formulation of the problem is a member of a rich VRP family 4, which is hard to solve optimally as it requires the joint solution several difficult subproblems. To overcome this barrier, we now present a GIS-based solution approach.

In practice, there are several commercial programs are available to solve the VRP and its 
extensive variations. GIS is a kind of system that provides spatial analyses and supports the decision-making activities by using various geographic data. It can also support logistic and marketing managers to evaluate placement options. Thus, GIS is used for replenishment of automated teller machines in Gaziantep [28]. We used the ArcGIS 10.2 commercial package to solve our optimization problem and also for building our GIS-based decision support framework. The ArcGIS is frequently used in many broad areas where spatially-enabled data need to be stored, retrieved, analyzed, visualized and even served online 29]. The ArcGIS is first used as a platform to store all problem data in geographic format. It visualizes all data as well as the solutions we obtain through our heuristic approach.

The software platform commercial package ArcGIS uses a tabu search heuristic algorithm to solve our defined problem. The solution method follows the classical tabu search principles such as non-improving solutions are accepted along the way. However, cycling of solutions are avoided using tabu lists and tabu tenure parameters [30. In the last decades, tabu search heuristics are commonly used in VRP and its variants. It obtains quite competetive solutions and it is still an highly effective heuristic method [31 33]. Initialization phase creates an origin-destination matrix of shortest travel costs between all locations that must be visited by a route. A feasible initial solution is then generated by inserting each location one at a time into the most suitable route. The improvement phase aims to obtain high quality solution by applying the following procedures.

- Changing the sequence nodes on a single route.

- Moving a single node from its current route to a better route.

- Swapping two nodes between their respective routes.

Figure 2 shows the framework of the system proposed in a form of a diagram.

\section{A case study}

We now present a case study arising in one of the major bank operating in Turkey. The considered bank group is an integrated financial services group operating in every segment of the banking sector including corporate, commercial, small and medium-sized enterprises, payment systems, retail, private and investment banking together with its subsidiaries in pension and life insurance, leasing, factoring, brokerage, and asset management. As of September 2017, the bank group provides a wide range of financial services to its tens of million customers through an extensive distribution network of 942 domestic branches with 4,769 ATMs.

To manage the money flow between branches and ATMs, the bank group aims to speed up decisionmaking and implementation processes by establishing a well-designed logistic network. To do so, one district office, 12 branches and 53 ATMs which are located in the city of Gaziantep are considered to be designed. The locations of the ATMs, and district office and branches are illustrated in Figures 3 and 4, respectively.

Gaziantep with its $1,975,302$ population in 2016 is the 8th most crowded city of Turkey and it is an important commercial and industrial center for Turkey. The considered stores are located in two districts which cover $85 \%$ of total population of Gaziantep. In total, there are 5 benchmark instances, i.e., GB-1, GB-2, GB-3, GB-4, and GB-5, which include all ATMs with different demands range from 5 to 45 money trays. Solving a network analysis problem in ArcGIS software, several parameters shown below have to be utilized in our study. Figure 5 shows an example of the user interface of ArcGIS of parameter entry. Table 1 presents the detailed information about benchmark instances. The first column shows the ATM number, while others present the daily demand.

- Vehicle number : Bank group has four vehicles.

- Vehicle Capacity: Each vehichle has the same capacity (200 money trays) and type.

- Each ATM has a service time which includes the loading money and handling paperwork for shipment.

- Start Depot: Each vehicle starts from district office.

- Maximum Travel Time: Each vehicles duration time is fixed at 6 hours.

- Vehicle Speed: Speed is fixed at $50 \mathrm{~km} / \mathrm{h}$.

- Distance Attribute: Road length is selected as distance attribute.

- Restrictions: One-way traffic is set as road restrictions.

\section{Computational experiments and analyses}

This section presents the results of the computational experiments. All experiments were conducted on a server with an Intel Core i7 CPU 3.07 
Table 1. The detailed information about benchmark instances.

\begin{tabular}{|c|c|c|c|c|c|}
\hline ATM No & GB1 & GB2 & GB3 & GB4 & GB5 \\
\hline 1 & 11 & 12 & 10 & 12 & 13 \\
\hline 2 & 22 & 23 & 21 & 23 & 24 \\
\hline 3 & 22 & 23 & 21 & 23 & 24 \\
\hline 4 & 11 & 12 & 10 & 12 & 13 \\
\hline 5 & 22 & 23 & 21 & 23 & 24 \\
\hline 6 & 11 & 12 & 10 & 12 & 13 \\
\hline 7 & 11 & 12 & 10 & 12 & 13 \\
\hline 8 & 22 & 23 & 21 & 23 & 24 \\
\hline 9 & 43 & 44 & 42 & 44 & 45 \\
\hline 10 & 17 & 18 & 16 & 18 & 19 \\
\hline 11 & 11 & 12 & 10 & 12 & 13 \\
\hline 12 & 11 & 12 & 10 & 12 & 13 \\
\hline 13 & 11 & 12 & 10 & 12 & 13 \\
\hline 14 & 17 & 18 & 16 & 18 & 19 \\
\hline 15 & 17 & 18 & 16 & 18 & 19 \\
\hline 16 & 11 & 12 & 10 & 12 & 13 \\
\hline 17 & 22 & 23 & 21 & 23 & 24 \\
\hline 18 & 22 & 23 & 21 & 23 & 24 \\
\hline 19 & 6 & 7 & 5 & 7 & 8 \\
\hline 20 & 22 & 23 & 21 & 23 & 24 \\
\hline 21 & 33 & 34 & 32 & 34 & 35 \\
\hline 22 & 22 & 23 & 21 & 23 & 24 \\
\hline 23 & 33 & 34 & 32 & 34 & 35 \\
\hline 24 & 33 & 34 & 32 & 34 & 35 \\
\hline 25 & 22 & 23 & 21 & 23 & 24 \\
\hline 26 & 22 & 23 & 21 & 23 & 24 \\
\hline 27 & 11 & 12 & 10 & 12 & 13 \\
\hline 28 & 33 & 34 & 32 & 34 & 35 \\
\hline 29 & 6 & 7 & 5 & 7 & 8 \\
\hline 30 & 11 & 12 & 10 & 12 & 13 \\
\hline 31 & 11 & 12 & 10 & 12 & 13 \\
\hline 32 & 11 & 12 & 10 & 12 & 13 \\
\hline 33 & 11 & 12 & 10 & 12 & 13 \\
\hline 34 & 11 & 12 & 10 & 12 & 13 \\
\hline 35 & 6 & 7 & 5 & 7 & 8 \\
\hline 36 & 6 & 7 & 5 & 7 & 8 \\
\hline 37 & 11 & 12 & 10 & 12 & 13 \\
\hline 38 & 11 & 12 & 10 & 12 & 13 \\
\hline 39 & 6 & 7 & 5 & 7 & 8 \\
\hline 40 & 6 & 7 & 5 & 7 & 8 \\
\hline 41 & 6 & 7 & 5 & 7 & 8 \\
\hline 42 & 11 & 12 & 10 & 12 & 13 \\
\hline 43 & 11 & 12 & 10 & 12 & 13 \\
\hline 44 & 17 & 18 & 16 & 18 & 19 \\
\hline 45 & 27 & 28 & 26 & 28 & 29 \\
\hline 46 & 27 & 28 & 26 & 28 & 29 \\
\hline 47 & 22 & 23 & 21 & 23 & 24 \\
\hline 48 & 22 & 23 & 21 & 23 & 24 \\
\hline 49 & 17 & 18 & 16 & 18 & 19 \\
\hline 50 & 33 & 34 & 32 & 34 & 35 \\
\hline 51 & 17 & 18 & 16 & 18 & 19 \\
\hline 52 & 17 & 18 & 16 & 18 & 19 \\
\hline 53 & 11 & 12 & 10 & 12 & 13 \\
\hline
\end{tabular}




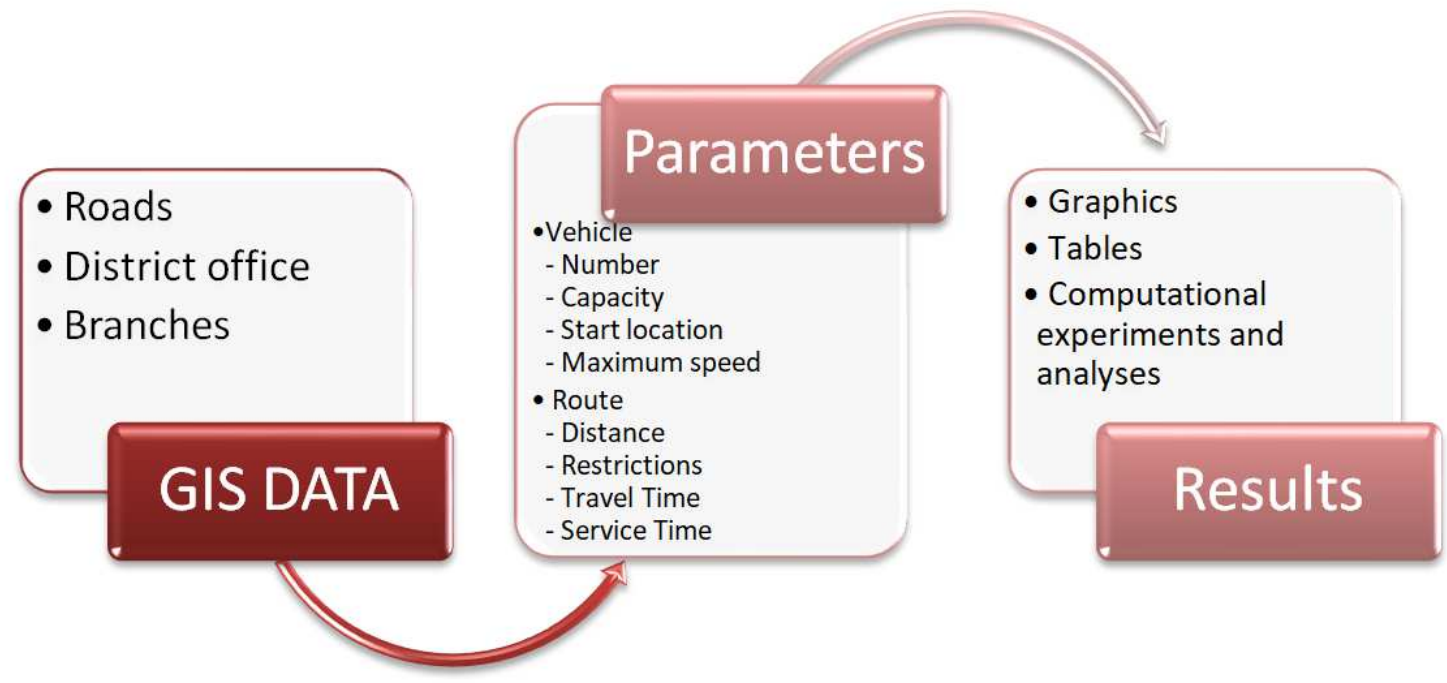

Figure 2. The framework of the system proposed in a form of a diagram.

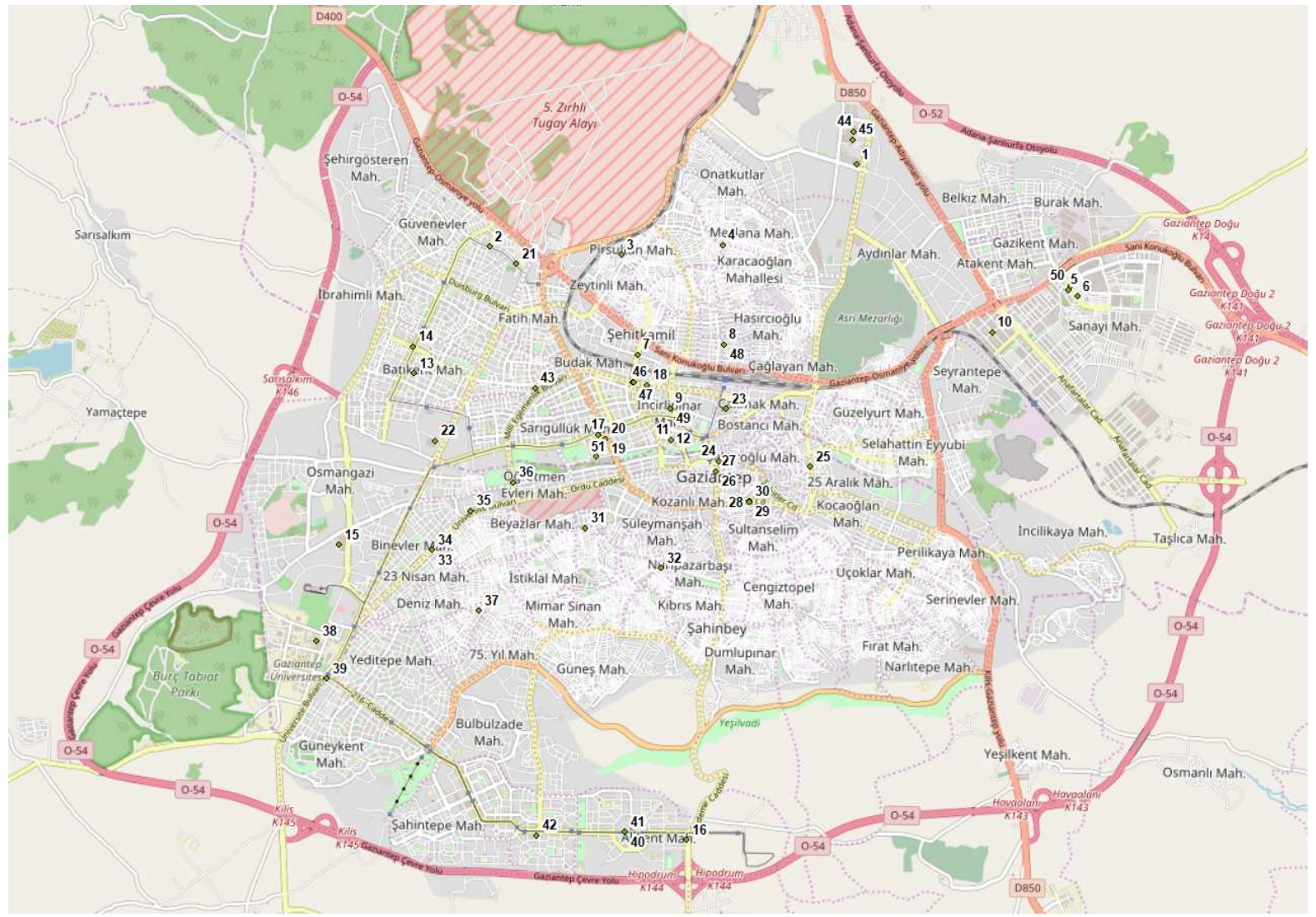

Figure 3. Locations of ATMs.

Ghz processor. The analysis of the ArcGIS for the case study has considered fixed parameters.

Tables 26 presents the results obtained on 5 benchmark instances of the bank. The illustrations of solutions are given in Figures 6 10, In our experiments, we first relax the starting from the district office and returning to the district office constraint and presents its results in the first part of the table. We then present the results of the considered problem in the second part of the table. In each table, the first column shows the vehicle and its tour number. For example, "1/1" indicates that the first vehicle's first tour. The second and third columns show the start and end nodes of the vehicle tour, respectively. The other columns show the total number of orders, total 


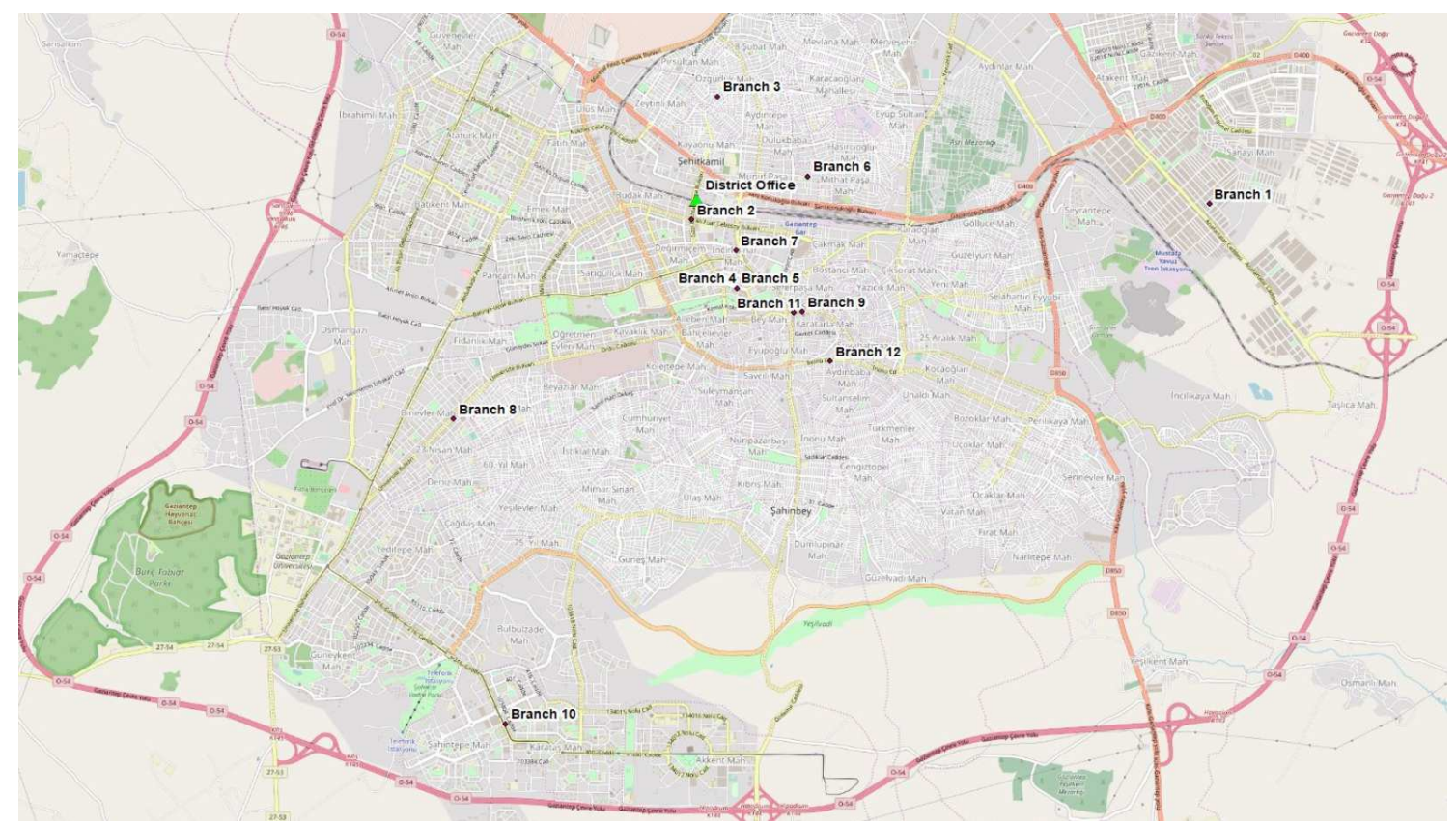

Figure 4. Locations of district office and branches.

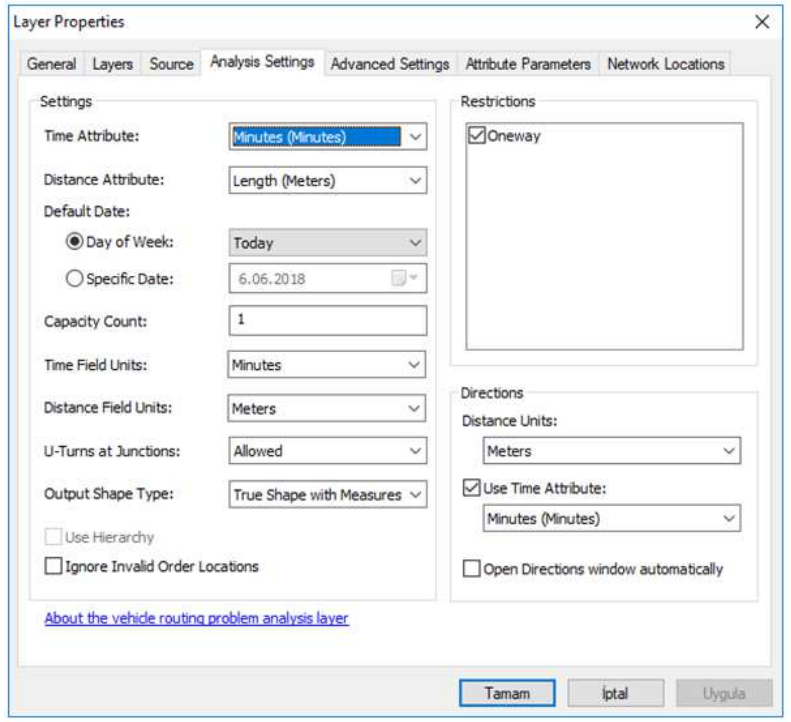

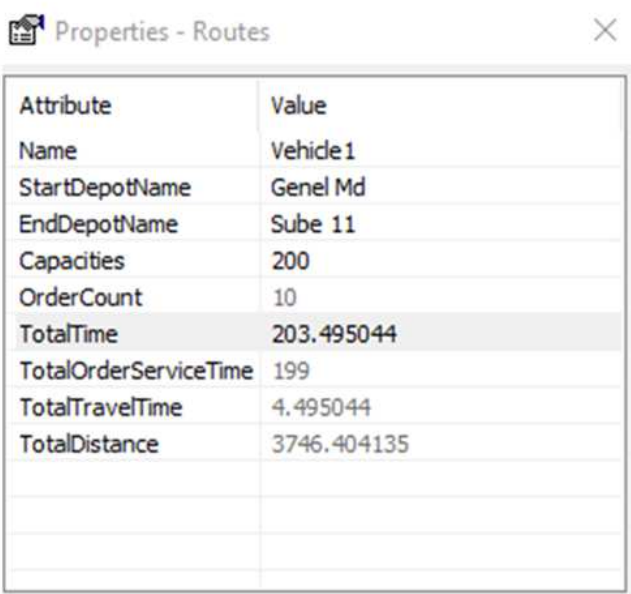

Figure 5. An example of the user interface of ArcGIS of parameter entry.

travel time (seconds), the total distance (km), total service time (seconds), and total en-route time (seconds), respectively.

Solution times for each instance are less than two seconds. Table 2 shows that all vehicles are used once. Tables 3. 4, and 5 show that vehicle 1 used two times, but vehicles 2,3 , and 4 only used once. Table 6 shows that vehicle 1 and 3 used two times, vehicles 2 and 4 used only once. Total distances are 84.32, 88.79, 84.76, 85.35, and 92.52 km for GB-1, GB-2, GB-3, GB-4, and GB-5, respectively. Total travel times are 101.17, 106.53,
101.70, 102.40, and 111.01 seconds for GB-1, GB2, GB-3, GB-4, and GB-5, respectively. Total enroute times are 879.17, 937.53, 985.70, 1039.40, and 1101.01, respectively.

When we remove the each vehicle route starts and ends at the depot constraint, Tables 226 show that vehicle 1 used two times, vehicle 2 used two times, and vehicle 3 used only once. Total distances are 69.67, 71.71, 70.74, 79.44, and $82.52 \mathrm{~km}$ for GB-1, GB-2, GB-3, GB-4, and GB-5, respectively. Total travel times are 83.59, 86.04, 84.88, 95.31, and 99.01 seconds for GB-1, GB-2, GB3, GB-4, and GB-5, respectively. Total en-route times are 861.59, 917.04, 968.88, 968.88, 1032.31, 
and 1089.01 seconds for GB-1, GB-2, GB-3, GB4, and GB-5, respectively.

When we compared our results with current one used by the bank for its daily operation, our results provided better solutions. On average, in terms of total distance, total travel times, and total en-route times, our method obtained $9.52 \%$, $10.51 \%$, and $10.65 \%$ better solutions. These results show that total distances are reduced when we relax each vehicle route starts and ends at the depot constraint. Similarly, total travel times and total en-route times are also reduced. Our results indicate that four vehicle are enough for satisfying ATM demands, and in general more than one vehicle tour is not necessary.

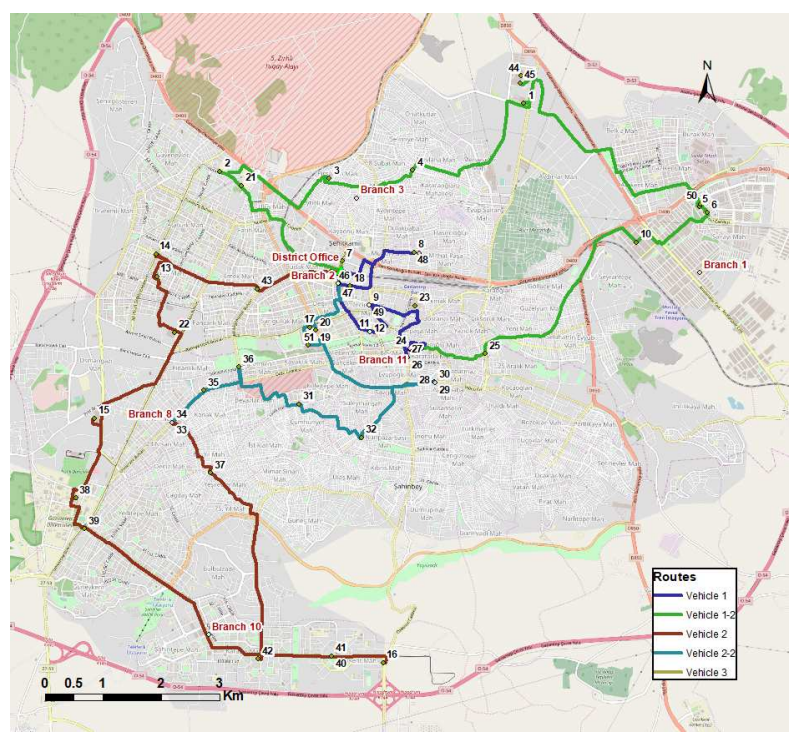

Figure 6. Solution of GB-1.

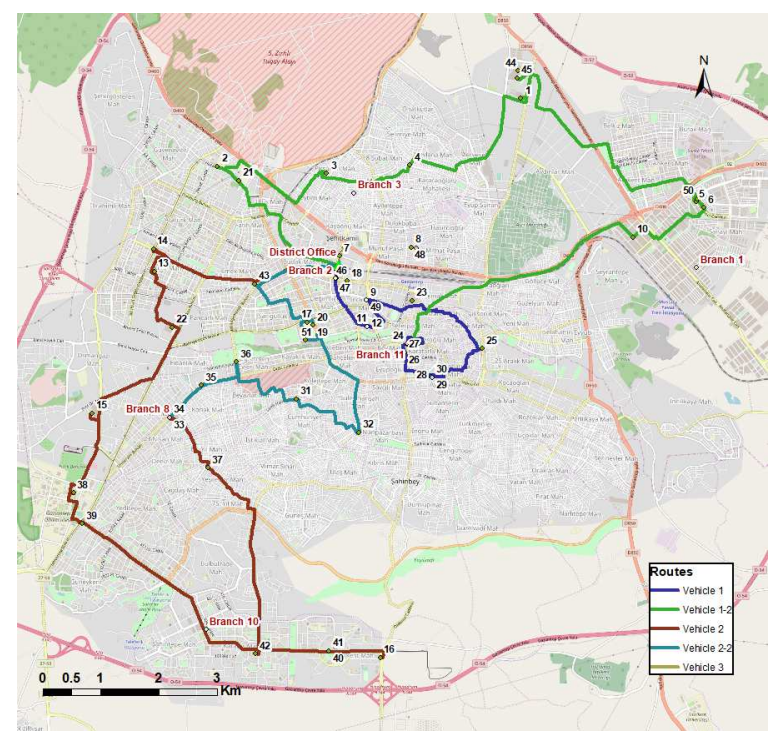

Figure 7. Solution of GB-2.

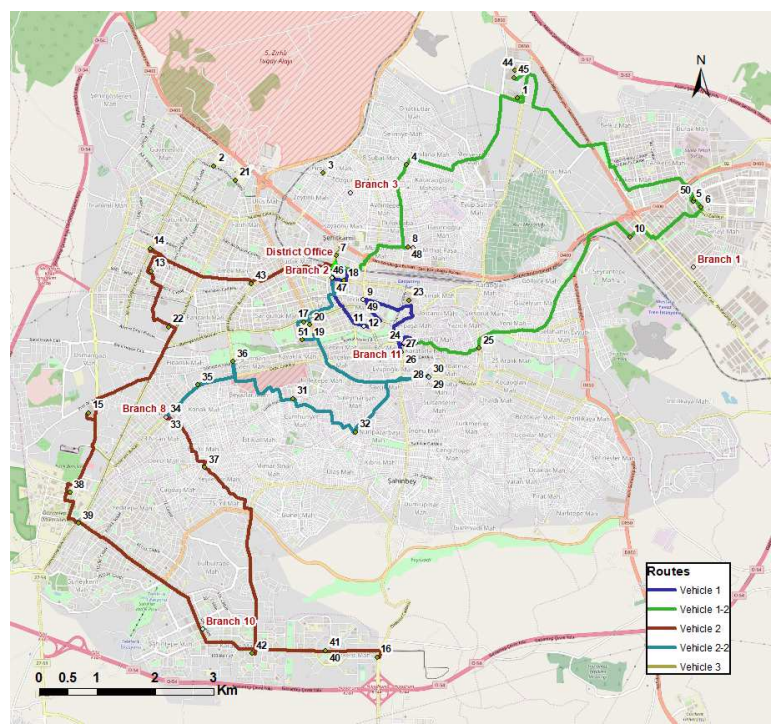

Figure 8. Solution of GB-3.

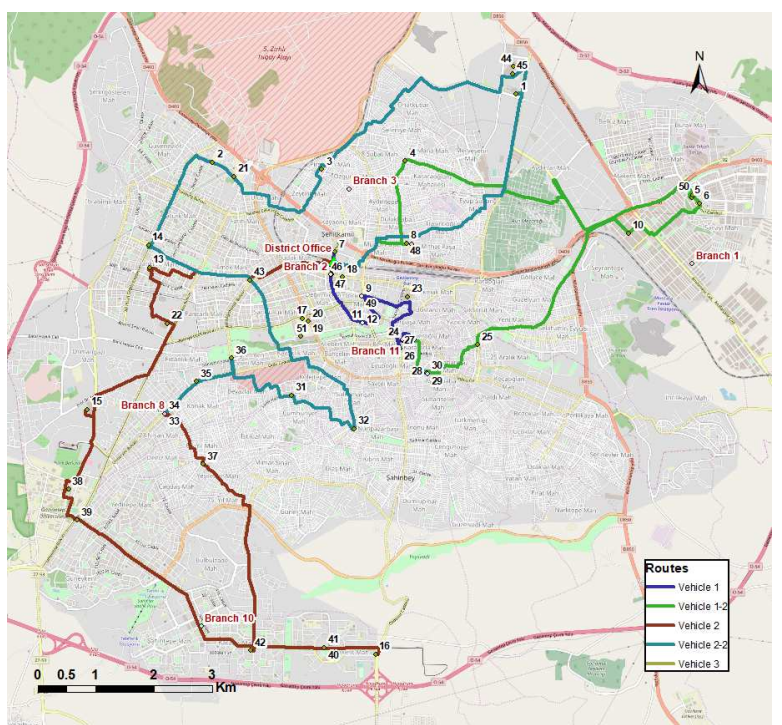

Figure 9. Solution of GB-4.

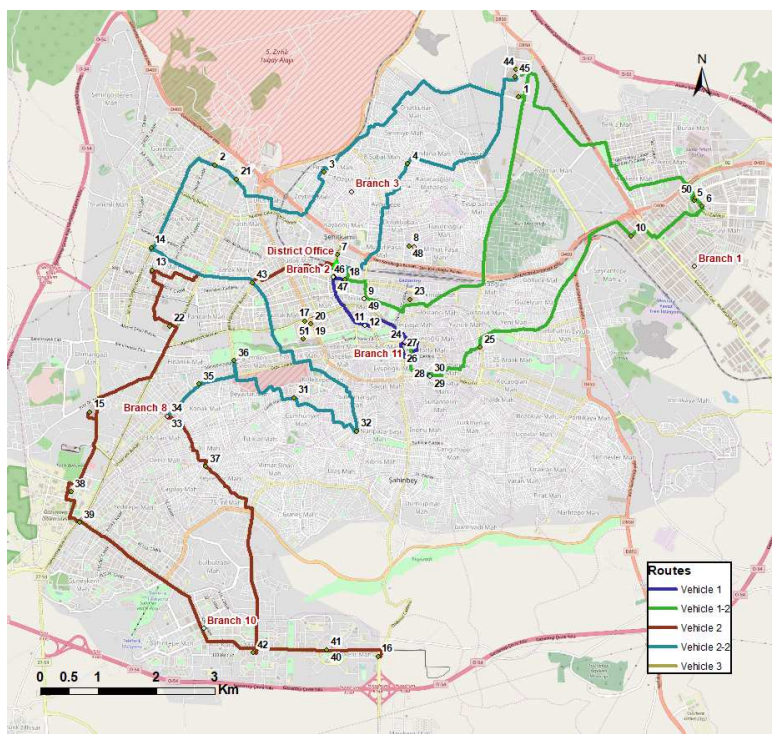

Figure 10. Solution of GB-5. 
Table 2. The detailed results of instance GB-1.

\begin{tabular}{llllllll}
\hline $\begin{array}{l}\text { Vehicle/ } \\
\text { Tour }\end{array}$ & Starting node & End node & $\begin{array}{l}\text { Total } \\
\text { order }\end{array}$ & $\begin{array}{l}\text { Total } \\
\text { distance }\end{array}$ & $\begin{array}{l}\text { Total } \\
\text { travel } \\
\text { time }\end{array}$ & $\begin{array}{l}\text { Total } \\
\text { service } \\
\text { time }\end{array}$ & $\begin{array}{l}\text { Total } \\
\text { en-route } \\
\text { time }\end{array}$ \\
\hline $1 / 1$ & District office & Branch 11 & 14 & 8.20 & 9.84 & 189 & 198.84 \\
$1 / 2$ & Branch 11 & District Office & 12 & 24.03 & 28.83 & 192 & 220.83 \\
$2 / 1$ & District Office & Branch 8 & 12 & 25.04 & 30.04 & 196 & 226.04 \\
$2 / 2$ & Branch 8 & District Office & 14 & 12.01 & 14.41 & 186 & 200.41 \\
$3 / 1$ & District Office & District Office & 1 & 0.39 & 0.47 & 15 & 15.47 \\
Total & & & 53 & 69.67 & 83.59 & 778 & 861.59 \\
& & & & & & & \\
$1 / 1$ & District Office & District Office & 18 & 23.60 & 28,32 & 196 & 224.32 \\
$2 / 1$ & District Office & District Office & 13 & 17.31 & 20,77 & 192 & 212.77 \\
$3 / 1$ & District Office & District Office & 13 & 25.06 & 30,07 & 200 & 230.07 \\
$4 / 1$ & District Office & District Office & 9 & 18.34 & 22,01 & 190 & 212.01 \\
Total & & & 53 & 84.32 & 101.17 & 778 & 879.17 \\
\hline
\end{tabular}

Table 3. The detailed results of instance GB-2.

\begin{tabular}{llllllll}
\hline $\begin{array}{l}\text { Vehicle/ } \\
\text { Tour }\end{array}$ & Starting node & End node & $\begin{array}{l}\text { Total } \\
\text { order }\end{array}$ & $\begin{array}{l}\text { Total } \\
\text { distance }\end{array}$ & $\begin{array}{l}\text { Total } \\
\text { travel } \\
\text { time }\end{array}$ & $\begin{array}{l}\text { Total } \\
\text { service } \\
\text { time }\end{array}$ & $\begin{array}{l}\text { Total } \\
\text { en-route } \\
\text { time }\end{array}$ \\
\hline $1 / 1$ & District Office & Branch 11 & 14 & 7.86 & 9.43 & 181 & 190.43 \\
$1 / 2$ & Branch 11 & District Office & 11 & 23.54 & 28.25 & 199 & 227.25 \\
$2 / 1$ & District Office & Branch 8 & 11 & 25.01 & 30.01 & 187 & 217.01 \\
$2 / 2$ & Branch 8 & District Office & 11 & 11.50 & 13.80 & 175 & 188.80 \\
$3 / 1$ & District Office & District Office & 6 & 3.80 & 4.56 & 89 & 93.56 \\
Total & & & 53 & 71.71 & 86.04 & 831 & 917.04 \\
& & & & & & & \\
$1 / 1$ & District Office & District Office & 14 & 26.57 & 31.88 & 168 & 199.88 \\
$1 / 2$ & District Office & District Office & 9 & 15.73 & 18.87 & 157 & 175.87 \\
$2 / 1$ & District Office & District Office & 12 & 16.89 & 20.26 & 184 & 204.26 \\
$3 / 1$ & District Office & District Office & 13 & 25.59 & 30.70 & 192 & 222.70 \\
$4 / 1$ & District Office & District Office & 5 & 4.02 & 4.82 & 130 & 134.82 \\
Total & & & 53 & 88.79 & 106.53 & 831 & 937.53 \\
\hline
\end{tabular}

Table 4. The detailed results of instance GB-3.

\begin{tabular}{llllllll}
\hline $\begin{array}{l}\text { Vehicle/ } \\
\text { Tour }\end{array}$ & Starting node & End node & $\begin{array}{l}\text { Total } \\
\text { order }\end{array}$ & $\begin{array}{l}\text { Total } \\
\text { distance }\end{array}$ & $\begin{array}{l}\text { Total } \\
\text { travel } \\
\text { time }\end{array}$ & $\begin{array}{l}\text { Total } \\
\text { service } \\
\text { time }\end{array}$ & $\begin{array}{l}\text { Total } \\
\text { en-route } \\
\text { time }\end{array}$ \\
\hline $1 / 1$ & District Office & Branch 11 & 12 & 5.20 & 6.24 & 195 & 201.24 \\
$1 / 2$ & Branch 11 & District Office & 12 & 19.61 & 23.53 & 200 & 223.53 \\
$2 / 1$ & District Office & Branch 8 & 11 & 25.01 & 30.01 & 198 & 228.01 \\
$2 / 2$ & Branch 8 & District Office & 13 & 11.96 & 14.35 & 197 & 211.35 \\
$3 / 1$ & District Office & District Office & 5 & 8.96 & 10.75 & 94 & 104.75 \\
Total & & & 53 & 70.74 & 84.88 & 884 & 968.88 \\
& & & & & & & \\
$1 / 1$ & District Office & District Office & 12 & 6.70 & 8.04 & 195 & 203.04 \\
$1 / 2$ & District Office & District Office & 10 & 20.37 & 24.44 & 197 & 221.44 \\
$2 / 1$ & District Office & District Office & 13 & 28.76 & 34.51 & 193 & 227.51 \\
$3 / 1$ & District Office & District Office & 7 & 11.63 & 13.95 & 127 & 140.95 \\
$4 / 1$ & District Office & District Office & 11 & 17.30 & 20.76 & 172 & 192.76 \\
Total & & & 53 & 84.76 & 101.70 & 884 & 985.70 \\
\hline
\end{tabular}


Table 5. The detailed results of instance GB-4.

\begin{tabular}{llllllll}
\hline $\begin{array}{l}\text { Vehicle/ } \\
\text { Tour }\end{array}$ & Starting node & End node & $\begin{array}{l}\text { Total } \\
\text { order }\end{array}$ & $\begin{array}{l}\text { Total } \\
\text { distance }\end{array}$ & $\begin{array}{l}\text { Total } \\
\text { travel } \\
\text { time }\end{array}$ & $\begin{array}{l}\text { Total } \\
\text { service } \\
\text { time }\end{array}$ & $\begin{array}{l}\text { Total } \\
\text { en-route } \\
\text { time }\end{array}$ \\
\hline $1 / 1$ & District Office & Branch 11 & 10 & 5.08 & 6,09 & 166 & 172.09 \\
$1 / 2$ & Branch 11 & District Office & 12 & 18.40 & 22,08 & 195 & 217.08 \\
$2 / 1$ & District Office & Branch 8 & 11 & 24.43 & 29,31 & 198 & 227.31 \\
$2 / 2$ & Branch 8 & District Office & 13 & 27.12 & 32,54 & 197 & 229.54 \\
$3 / 1$ & District Office & District Office & 7 & 4.41 & 5.29 & 181 & 186.29 \\
Total & & & 53 & 79.44 & 95.31 & 937 & 1032.31 \\
& & & & & & & \\
$1 / 1$ & District Office & District Office & 11 & 6.70 & 8.04 & 189 & 197.04 \\
$1 / 2$ & District Office & District Office & 11 & 16.16 & 19.39 & 194 & 213.39 \\
$2 / 1$ & District Office & District Office & 11 & 17.59 & 21.11 & 197 & 218.11 \\
$3 / 1$ & District Office & District Office & 8 & 13.55 & 16.26 & 167 & 183.26 \\
$4 / 1$ & District Office & District Office & 12 & 31.35 & 37.61 & 190 & 227.61 \\
Total & & & 53 & 85.35 & 102.40 & 937 & 1039.40 \\
\hline
\end{tabular}

Table 6. The detailed results of instance GB-5.

\begin{tabular}{llllllll}
\hline $\begin{array}{l}\text { Vehicle/ } \\
\text { Tour }\end{array}$ & Starting node & End node & $\begin{array}{l}\text { Total } \\
\text { order }\end{array}$ & $\begin{array}{l}\text { Total } \\
\text { distance }\end{array}$ & $\begin{array}{l}\text { Total } \\
\text { travel } \\
\text { time }\end{array}$ & $\begin{array}{l}\text { Total } \\
\text { service } \\
\text { time }\end{array}$ & $\begin{array}{l}\text { Total } \\
\text { en-route } \\
\text { time }\end{array}$ \\
\hline $1 / 1$ & District Office & Branch 11 & 10 & 3.75 & 4.50 & 199 & 203.50 \\
$1 / 2$ & Branch 11 & District Office & 11 & 20.77 & 24.92 & 199 & 223.92 \\
$2 / 1$ & District Office & Branch 8 & 10 & 24.43 & 29.31 & 196 & 225.31 \\
$2 / 2$ & Branch 8 & District Office & 13 & 2664 & 31.96 & 199 & 230.96 \\
$3 / 1$ & District Office & District Office & 9 & 6.94 & 8.33 & 197 & 205.33 \\
Total & & & 53 & 82.52 & 99.01 & 990 & 1089.01 \\
& & & & & & & \\
$1 / 1$ & District Office & District Office & 12 & 13.02 & 15.63 & 175 & 190.63 \\
$1 / 2$ & District Office & District Office & 9 & 30.10 & 36.11 & 190 & 226.11 \\
$2 / 1$ & District Office & District Office & 10 & 17.57 & 21.08 & 175 & 196.08 \\
$3 / 1$ & District Office & District Office & 11 & 25.26 & 30.31 & 198 & 228.31 \\
$3 / 2$ & District Office & District Office & 3 & 1.04 & 1.24 & 62 & 63.24 \\
$4 / 1$ & District Office & District Office & 8 & 5.53 & 6.64 & 190 & 196.64 \\
Total & & & 53 & 92.52 & 111.01 & 990 & 1101.01 \\
\hline
\end{tabular}

\section{Conclusions}

This paper has been motivated by the problem faced by one of the major banks of Turkey operating in the city of Gaziantep. We have defined a new rich vehicle routing problem which is concerned with the joint multiple depots, pickup and delivery, multi-trip, and homogeneous fixed vehicle fleet. We have presented a mathematical formulation for the problem. To obtain fast and good quality solutions, we have then used a GISbased solution approach employs a tabu search algorithm which can be used to store, analyze and visualize all data as well as model solutions in geographic format. We have considered a real dataset of the bank and have applied our GIS-based solution approach. We have finally provided several managerial and policy insights on results by exploring the problem.

Our results indicated that four vehicles are enough to satisfy the demand of ATMs for the bank and one vehicle tour is also enough for each vehicle in general. We have also shown that total distances are reduced if we do not consider each vehicle route starts and ends at the depot constraint. In a similar manner, total travel times and total en-route times are also reduced. Furthermore, the running times of the algorithm are so small that it can be used in practical bank operations.

For future studies, stochasticity and dynamism can be taken account in the problem definition, instead of using deterministic parameters. This 
would require new mathematical models and solution algorithms, such as stochastic optimization. Furthermore, new effective exact methods can be developed, such as Lagrangean relaxation to obtain lower bounds, or decomposition techniques to solve large size benchmark instances to optimality.

\section{Acknowledgements}

The authors thank the three anonymous referees for their insightful comments and suggestions that helped improve the content and the presentation of the paper.

\section{References}

[1] Özceylan, E., Uslu, A., Erbaş, M., Çetinkaya, C., İşleyen, S. K. (2017). Optimizing the locationallocation problem of pharmacy warehouses: A case study in Gaziantep. An International Journal of Optimization and Control: Theories \& Applications (IJOCTA), 7, 117-129.

[2] Laporte, G. (2009). Fifty years of vehicle routing. Transportation Science, 43, 408-416.

[3] Toth, P. Vigo, D., eds. (2014). Vehicle routing: Problems, methods, and applications. MOS-SIAM Series on Optimization, Philadelphia.

[4] Lahyani, R., Khemakhem, M., Semet, F. (2015). Rich vehicle routing problems: From a taxonomy to a definition. European Journal of Operational Research, 241, 1-14.

[5] Karaoglan, A. D., Gonen, D., Ucmus, E. (2011). Aircraft routing and scheduling: A case study in an airline company. An International Journal of Optimization and Control: Theories \& Applications (IJOCTA), 1, 27-43.

[6] Karagul, K., Gungor, I. (2014). A case study of heterogeneous fleet vehicle routing problem: Touristic distribution application in Alanya. An International Journal of Optimization and Control: Theories \& Applications (IJOCTA), 4, 67-76.

[7] Van Anholt, R. G., Coelho, L. C., Laporte, G., Vis, I. F. (2016). An inventory-routing problem with pickups and deliveries arising in the replenishment of automated teller machines. Transportation Science, 50, 1077-1091.

[8] Karagul, K., Aydemir, E., Tokat, S. (2016). Using 2Opt based evolution strategy for travelling salesman problem. An International Journal of Optimization and Control: Theories \& Applications (IJOCTA), 6, 103-113.

[9] Crevier, B., Cordeau, J. F., Laporte, G. (2007). The multi-depot vehicle routing problem with inter-depot routes. European Journal of Operational Research, 176, 756-773.

[10] Braekers, K., Caris, A., Jenssens, G. K. (2014). Exact and meta-heuristic approach for a general heterogeneous dial-a-ride problem with multiple depots. Transportation Research Part B, 67, 166-186.

[11] Contardo, C., Martinelli, R. (2014). A new exact algorithm for the multi-depot vehicle routing problem under capacity and route length constraints. Discrete Optimization, 12, 129-146.
[12] Montoya-Torres, J. R., Franco, J. L., Isaza, S. N., Jimnez, H. F., Herazo-Padilla, N. (2015). A literature review on the vehicle routing problem with multiple depots. Computers \& Industrial Engineering, 79, 115129.

[13] Koç, Ç., Karaoğlan, İ. (2012). A mathematical model for the vehicle routing problem with time windows and multiple use of vehicles. Journal of the Faculty of Engineering and Architecture of Gazi University, 27, 569-576.

[14] Cattaruzza, D., Absi, N., Feillet, D., Vidal, T. (2014). A memetic algorithm for the multi trip vehicle routing problem. European Journal of Operational Research, 236, 833-848.

[15] Olivera, A., Viera, O. (2007). Adaptive memory programming for the vehicle routing problem with multiple trips. Computers \& Operations Research, 34, 2847.

[16] Xu, H., Chen, Z. L., Rajagopal, S., Arunapuram, S. (2003). Solving a practical pickup and delivery problem. Transportation Science, 37, 347-364.

[17] Sigurd, M., Pisinger, D., Sig, M. (2004). Scheduling transportation of live animals to avoid the spread of diseases. Transportation Science, 38, 197-209.

[18] Battarra, M., Cordeau, J-F., Iori, M. (2014). Pickupand-delivery problems for goods transportation. In Toth, P. Vigo, D., eds. Vehicle Routing: Problems, Methods, and Applications (pp. 161-192). MOSSIAM Series on Optimization, Philadelphia.

[19] Berbeglia, G., Cordeau, J.-F., Gribkovskaia, I., Laporte, G. (2007). Static pickup and delivery problems: A classification scheme and survey. TOP: An Official Journal of the Spanish Society of Statistics and Operations Research, 15, 1-31.

[20] Koç, Ç., Laporte, G. (2018). Vehicle routing with backhauls: Review and research perspectives. Computers \& Operations Research, 91, 79-91.

[21] Parragh, S. N., Doerner, K. F., Hartl, R. F. (2008a). A survey on pickup and delivery problems. Part I: Transportation between customers and depot. Journal für Betriebswirtschaft, 58, 21-51.

[22] Parragh, S. N., Doerner, K. F., Hartl, R. F. (2008b). A survey on pickup and delivery problems. Part II: Transportation between pickup and delivery locations. Journal für Betriebswirtschaft, 58, 81-117.

[23] Casas, I., Malik, A., Delmelle, E. M., Karwan, M. H., Batta, R. (2007). An automated network generation procedure for routing of unmanned aerial vehicles (UAVs) in a GIS environment. Networks and Spatial Economics, 7, 153-176.

[24] Bozkaya, B., Yanik, S., Balcisoy, S. (2010). A GISbased optimization framework for competitive multifacility location-routing problem. Networks and Spatial Economics, 10, 297-320.

[25] Samanlioglu, F. (2013). A multi-objective mathematical model for the industrial hazardous waste locationrouting problem. European Journal of Operational Research, 226, 332-340.

[26] Yanik, S., Bozkaya, B., de Kervenoael, R. (2014). A new VRPPD model and a hybrid heuristic solution approach for e-tailing. European Journal of Operational Research, 236, 879-890.

[27] Krichen, S., Faiz, S., Tlili, T., Tej, K. (2014). Tabubased GIS for solving the vehicle routing problem. Expert Systems with Applications, 41, 6483-6493. 
[28] Vlachopoulou, M., Silleos, G., Manthou, V. (2001). Geographic information systems in warehouse site selection decisions. International Journal of Production Economics, 71, 205-212.

[29] ArcGIS, (2017). ArcGIS Network Analyst Tutorial. http://desktop.arcgis.com/en/arcmap/.

[30] Glover, F.W., Laguna, M. (1998). Tabu search. Kluwer Academic, Massachusetts.

[31] Brandão, J. (2009). A deterministic tabu search algorithm for the fleet size and mix vehicle routing problem. European Journal of Operational Research, 195, 716-728.

[32] Brandão, J. (2011). A tabu search algorithm for the heterogeneous fixed fleet vehicle routing problem. Computers \& Operations Research, 38, 140-151.

[33] Gendreau, M., Hertz, A., Laporte, G. (1994). A tabu search heuristic for the vehicle routing problem. Management Science, 40, 1276-1290.

Çăgrı Koç is an Assistant Professor in Department of Business Administration at Social Sciences University of Ankara. He was a Postdoctoral Fellow at HEC Montreal, Canada Research Chair in Distribution Management, and at CIRRELT (Interuniversity Research Center on Enterprise Networks, Logistics and Transportation). He received his Ph.D. degree (2015) in Management Science from the Southampton Business School of University of Southampton.
He is the recipient of the Operational Research Society 2015 Doctoral Dissertation Award. His research mainly focuses on transportation and logistics, supply chain management, vehicle routing and scheduling, and mathematical and metaheuristic optimization.

Mehmet Erbaş is working in General Directorate of Mapping, Ministry of National Defense. He worked as a Lecturer in the Geomatics Division of the Department of Civil Engineering Geomatics Division at the Turkish Military Academy in Ankara. His research and teaching interests focus on the topics of the geographic information systems and remote sensing applications.

Eren Özceylan is an Associate Professor in Department of Industrial Engineering at Gaziantep University. He received his Ph.D. degree in Computer Engineering from Seluk University in 2013. His research focuses on logistics and supply chain management. In particular, he focuses on supply chain network design, environmental conscious production/distribution, multi-criteria decision-making and fuzzy logic.

An International Journal of Optimization and Control: Theories \& Applications (http://ijocta.balikesir.edu.tr)

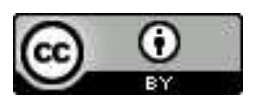

This work is licensed under a Creative Commons Attribution 4.0 International License. The authors retain ownership of the copyright for their article, but they allow anyone to download, reuse, reprint, modify, distribute, and/or copy articles in IJOCTA, so long as the original authors and source are credited. To see the complete license contents, please visit http://creativecommons.org/licenses/by/4.0/. 